Revista Brasileira de Agricultura Irrigada v.9, nº.3, p. 91 - 101, 2015

ISSN 1982-7679 (On-line)

Fortaleza, CE, INOVAGRI - http://www.inovagri.org.br

DOI: $10.7127 /$ rbai.v9n300275

Protocolo 275.15 - 29/12/2014 Aprovado em 10/05/2015

\title{
PERFILHAMENTO DA CANA-DE-AÇÚCAR SUBMETIDA A DIFERENTES LÂMINAS DE IRRIGAÇÃO E FERTIRRIGAÇ̃̃O NITROGENADA
}

\author{
Nelmício Furtado da Silva ${ }^{1}$, Fernando Nobre Cunha ${ }^{2}$, Marconi Batista Teixeira ${ }^{3}$, Frederico \\ Antonio Loureiro Soares ${ }^{4}$, Lígia Campos de Moura $^{5}$ Vitor Marques Vidal ${ }^{6}$
}

\begin{abstract}
RESUMO
Objetivou-se com este trabalho avaliar o número de perfilhos e número de plantas de cana-deaçúcar, submetida a diferentes lâminas de irrigação (100, 75, 50, 25 e 0\% de reposição hídrica), com a aplicação de nitrogênio (N) via água de irrigação (Fertirrigação) por gotejamento subsuperficial nas condições de cana-planta e soca. $\mathrm{O}$ experimento foi conduzido na área experimental do Instituto Federal Goiano - Campus Rio Verde, GO. O delineamento experimental utilizado foi em blocos ao acaso, analisado em esquema fatorial $5 \times 2 \times 2 \mathrm{com}$ quatro repetições. Os resultados foram submetidos à análise da variância pelo teste $\mathrm{F}$ ao nível de 5\% de probabilidade, e em casos de significância, foi realizada a análise de regressão para os níveis de reposição hídrica, enquanto para o fator aplicação de nitrogênio e ciclo as médias foram comparadas entre si pelo teste Tukey à $5 \%$ de probabilidade, utilizando-se o software estatístico Sisvar. Houve relação direta entre aplicação da irrigação por gotejamento subsuperficial e ciclo de cultivo, nas variáveis número de perfilhos e número de plantas, analisadas ao longo das fases de crescimento e desenvolvimento da cana-de-açúcar. A canasoca mostrou ter maior dependência de irrigação em relação à cana-planta no que diz respeito às variáveis número de perfilhos e número de plantas.
\end{abstract}

Palavras-chave: Saccharum officinarum L., gotejamento subsuperficial, ciclos de cultivo, número de plantas.

\section{TILLERING OF SUGAR CANE UNDER DIFFERENT IRRIGATION LEVELS AND NITROGEN FERTIGATION}

\footnotetext{
ABSTRACT

${ }^{1}$ Eng. Agrônomo, Doutorando em Ciências Agrárias - Agronomia, Laboratório de Hidráulica e Irrigação do Instituto Federal Goiano - Campus Rio Verde, Rodovia Sul Goiana, Km 01, CEP: 75.901-970, Rio Verde - GO, e-mail: nelmiciofurtado@gmail.com

${ }^{2}$ Eng. Agrônomo, Doutorando em Ciências Agrárias - Agronomia, IFGoiano - Campus Rio Verde, e-mail: fernandonobrecunha@hotmail.com

${ }^{3}$ Eng. Agrônomo, Prof. Dr. em Agronomia, IFGoiano - Campus Rio Verde, e-mail: marconibt@gmail.com

${ }^{4}$ Eng. Agrônomo, Prof. Dr. em Agronomia, IFGoiano - Campus Rio Verde, e-mail:fredalsoares@ @otmail.com

${ }^{5}$ Mestranda em Zootecnia, Instituto Federal Goiano - Campus Rio Verde, e-mail: ligiacamposmoura@gmail.com

${ }^{6}$ Eng. Agrícola, Doutorando em Ciências Agrárias - Agronomia, IFGoiano - Campus Rio Verde, e-mail: vmarquesvidal@gmail.com.
} 
The objective of this study was to evaluate the number of tillers and number of plants sugar cane, under different irrigation levels $(100,75,50,25$ and $0 \%$ fluid replacement), with the application of nitrogen $(\mathrm{N})$ through irrigation water (fertigation) subsurface drip under the conditions of cane plant and ratoon. The experiment was carried out at the experimental station of the Federal Institute Goiano - Campus Rio Verde - GO. The experimental design was a randomized block, analyzed in a factorial $5 \times 2 \times 2$ with four replications. The results were submitted to analysis of variance by $\mathrm{F}$ test at $5 \%$ probability, and in cases of significance, regression analysis was performed to the levels of water replacement, while for nitrogen application cycle factor and the means were compared by Tukey test at 5\% probability, using the statistical software Sisvar. There was a direct relationship between application of subsurface drip irrigation and crop cycle, the variables number of tillers variables and number of plants analyzed through the stages of growth and development of sugarcane. The ratoon shown to have greater reliance on irrigation in relation to plant cane as the variables number of tillers and number of plants.

Keywords: Saccharum officinarum L., subsurface drip irrigation, cultivation cycles, number of plants.

\section{INTRODUÇÃO}

O Brasil é o maior produtor mundial de cana-de-açúcar e de seus derivados, açúcar e álcool. A cana-de-açúcar é atualmente uma cultura de crescente importância econômica, considerada uma das principais commodities agrícolas em termos de produtividade (DEVOS, 2010).

A introdução da cana-de-açúcar no estado de Goiás exige estudos que discutam a adaptação e o desenvolvimento desses materiais sob as condições edafoclimáticas do Estado. Além disso, o fator irrigação que abrange desde o tipo de sistema a ser utilizado, a quantidade de água a ser aplicada e até mesmo a fertirrigação, traz a necessidade de estudos que gerem informações que possam contribuir para o desenvolvimento deste setor. No entanto, muitos produtores partem para a irrigação sem um planejamento adequado, sem considerar as necessidades hídricas, o manejo apropriado da água na cultura e sem conhecer as peculiaridades fisiológicas do crescimento da cana irrigada (DANTAS NETO et al., 2006). Por isso, a irrigação no Brasil está demandando necessariamente equipamentos que possam distribuir a água com mais eficiência, evitando desperdícios, e, estudos mais precisos sobre fatores fisiológicos, pedológicos e climáticos, que determinam a quantidade correta de água a ser utilizada (MARCUZZO, 2008).

Para o uso eficiente da água pela cana-deaçúcar, é fundamental identificar a necessidade hídrica responsável pelas máximas produções (WIEDENFELD \& ENCISO, 2008). A diferença de eficiência de utilização de água em relação à produtividade de colmos, verificada nos genótipos se deve sem dúvida, à capacidade que cada genótipo possui de tolerar o estresse hídrico e, em seguida, rapidamente se regenerar (SMIT \& SINGELS, 2006).

Segundo Inman-Bamber \& Smith (2005), a água é considerada fator limitante à produção da cana-de-açúcar, pois, à medida que sua disponibilidade aumenta, a cultura expressa seu potencial produtivo com diferentes respostas entre as variedades. Um conhecimento adequado de como os vegetais respondem a tal estresse abiótico e um dos pré-requisitos para escolher tanto a melhor variedade como as melhores práticas de manejo, visando, sobretudo, aperfeiçoar a exploração dos recursos naturais (SMIT \& SINGELS, 2006).

A cana-de-açúcar uma vez em contato com o solo, em condições favoráveis de umidade e temperatura, brota por intermédio da gema, a qual irá formar os novos colmos. A fase de perfilhamento intenso da touceira ocorre quando 
é atingido o máximo da produção de perfilhos, chegando algumas variedades a produzir 25 ou mais colmos por touceira. A partir do ponto de máximo perfilhamento, a competição entre os perfilhos pelos fatores de crescimento (luz, espaço, água e nutrientes) acentua se, de maneira que se constata a diminuição e paralisação deste processo, além da morte dos perfilhos mais novos (SEGATO et al., 2006).

O perfilhamento constitui uma etapa muito importante no ciclo da cultura, pois determina o número de plantas que irá formar os futuros colmos, que por sua vez representam a parte produtiva da cana-de-açúcar interferindo diretamente na obtenção de altas produtividades. Oliveira et al. (2010) ressaltam que a avaliação de algumas variáveis morfológicas das plantas como número de plantas por metro linear torna possível a identificação da capacidade produtiva da cultura, além de analisar os efeitos do manejo cultural adotado sobre a espécie.

Este trabalho de pesquisa partiu da hipótese de que a irrigação e a adubação nitrogenada têm o potencial de mitigar estes efeitos da deficiência hídrica na cana-de-açúcar mantendo um perfilhamento e stand de plantas adequados durante os ciclos de cultivo. Dessa forma, objetivou-se com este trabalho avaliar o número de perfilhos e número de plantas de cana-de-açúcar, submetidas a diferentes lâminas de irrigação $(100,75,50,25$ e $0 \%$ de reposição hídrica), com a aplicação de nitrogênio $(\mathrm{N})$ via água de irrigação (Fertirrigação) por gotejamento subsuperficial nas condições de cana-planta e soca.

\section{MATERIAL E MÉTODOS}

O experimento foi conduzido na área experimental do Instituto Federal Goiano Campus Rio Verde, GO, localizada na latitude $17^{\circ} 48^{\prime} 28^{\prime \prime} \mathrm{S}$ e longitude $50^{\circ} 53^{\prime} 57^{\prime}$ 'O, com altitude média de 720 metros e relevo suave ondulado (6\% de declividade). O clima da região foi classificado conforme Köppen, como Aw (tropical), com precipitação nos meses de outubro a maio, e com seca nos meses de junho a setembro. A temperatura média anual varia de 20 a $35{ }^{\circ} \mathrm{C}$ e as precipitações variam de 1.500 a $1.800 \mathrm{~mm}$ anuais. $\mathrm{O}$ solo foi classificado como Latossolo Vermelho distroférrico (LVdf) de textura média (EMBRAPA, 2006). Na Tabela 1 são apresentadas as características físico-hídricas e químicas do solo.

Tabela 1. Características físico-hídricas e químicas do solo da área experimental, nas camadas de 0-0,20 e $0,20-0,40 \mathrm{~m}$ de profundidade.

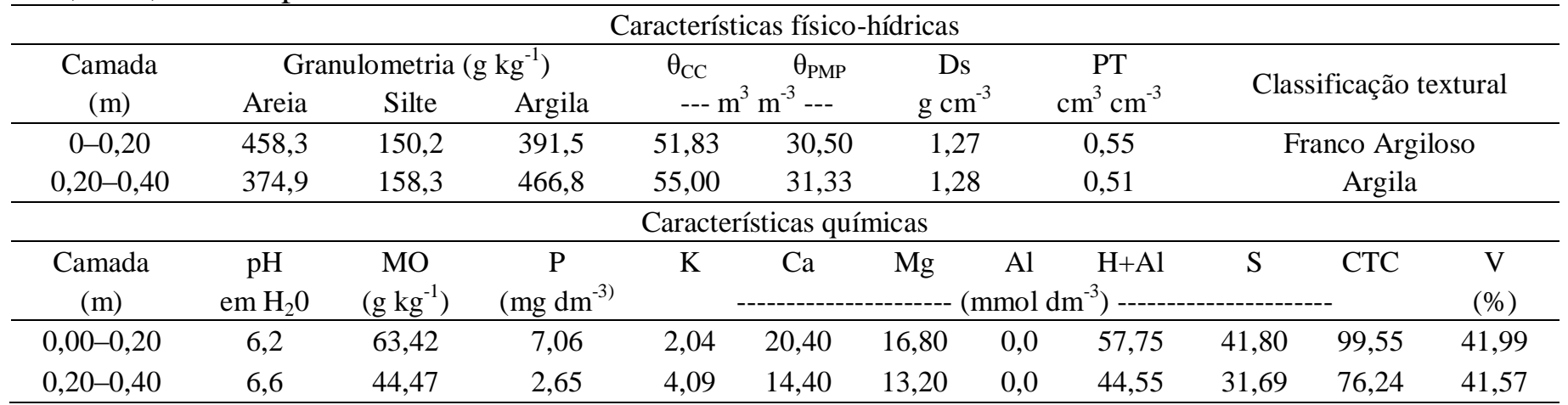

$\theta_{\mathrm{CC}}$, capacidade de campo; $\theta_{\mathrm{PMP}}$, ponto de murcha permanente; Ds, densidade do solo; PT, porosidade total; M.O - Matéria orgânica. V - Saturação por bases.

O delineamento experimental utilizado foi o de blocos ao acaso, analisado em esquema fatorial $5 \times 2 \times 2$, com quatro repetições. Os tratamentos consistiram em cinco níveis de reposição hídrica $(100,75,50,25$ e $0 \%$ de umidade do solo na capacidade de campo) 
combinados sem e com aplicação de fertilizante nitrogenado (0 e $100 \mathrm{~kg} \mathrm{ha}^{-1} \mathrm{de} \mathrm{N}$ ) na forma de ureia; durante ciclo de cana-planta e soca.

O plantio da cana-de-açúcar foi realizado em março de 2011, utilizando-se a variedade RB 85-5453, que apresenta como características principais alto teor de açúcar e precocidade. As parcelas experimentais foram compostas por três sulcos de linha dupla (plantio "em W") com espaçamento de 1,40 x $0,4 \mathrm{~m}$ e $8 \mathrm{~m}$ de comprimento, totalizando $43,2 \mathrm{~m}^{2}$ de área total por parcela (Figura 1).

Nos tratamentos com reposição hídrica, foi utilizado o método de irrigação por gotejamento subsuperficial. O tubo gotejador foi enterrado a 0,20 $\mathrm{m}$ de profundidade da superfície do solo, no meio da linha dupla (Figura 1), sendo que o mesmo apresentava as seguintes características: modelo Dripnet PC 16150 com parede delgada, pressão de serviço de 1 bar, vazão nominal de $1,0 \mathrm{~L} \mathrm{~h}^{-1} \mathrm{e}$ espaçamento entre gotejadores de $0,50 \mathrm{~m}$.

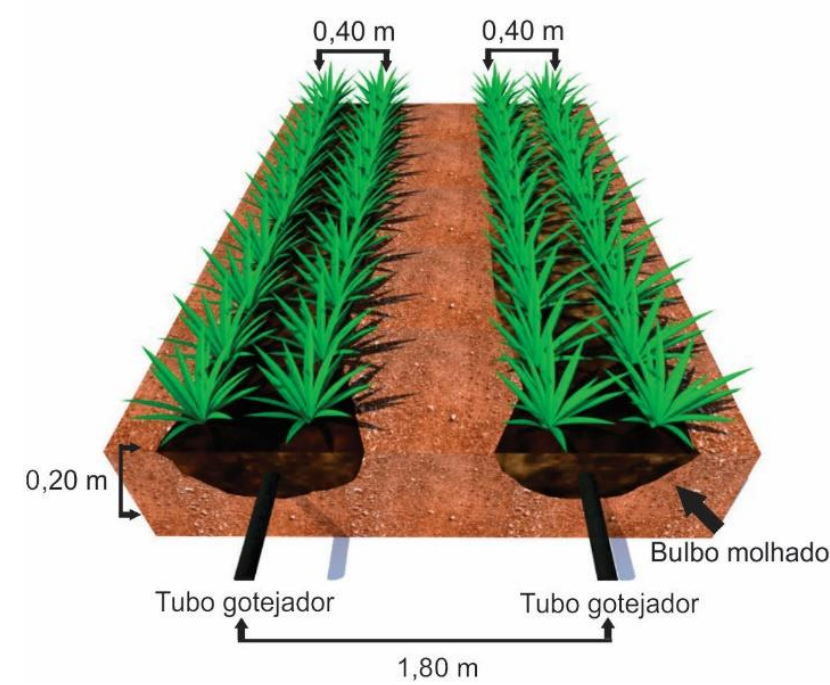

Figura 1. Representação esquemática do plantio em "W" e da disposição dos tubos gotejadores nos tratamentos com reposição hídrica. Fonte: Batista e Teixeira (2013).

O manejo da irrigação foi realizado por meio da tensiometria. A tensão foi determinada com um tensímetro digital de punção com sensibilidade de $0,1 \mathrm{kPa}$, sendo as hastes tensiométricas instaladas nas profundidades de 0,20, 0,40 $\mathrm{m}$ de profundidade e distâncias de $0,15,0,30,0,45$ e $0,60 \mathrm{~m}$ do tubo gotejador, sendo que, para o manejo da irrigação foi utilizado a profundidade e $0,20 \mathrm{~m}$, com leitura do potencial matricial do solo $(\Psi \mathrm{m})$ registrada diariamente.

Para determinar o momento da irrigação, utilizou-se tensão crítica de $50 \mathrm{KPa}$. As características físico-hídricas do solo foram determinadas mediante a curva de retenção de água no solo. Uma equação foi ajustada, de acordo com o modelo de van Genuchten (1980), para converter o $\Psi \mathrm{m}$ em conteúdo de água no solo $(\theta)$, minimizando a soma dos quadrados dos desvios utilizando-se o software RETEC (van Genuchten, 2009), obtendo, assim, os parâmetros empíricos de ajuste utilizados na equação apresentada a seguir:

$$
\theta=\theta_{r}+\frac{\theta_{s}-\theta_{r}}{\left[1+\left(\alpha \times\left|\psi_{m}\right|\right)^{n}\right]^{m}}
$$

em que:

$\theta-$ conteúdo de água no solo, $\mathrm{cm}^{3} \mathrm{~cm}^{-3}$;

$\Psi_{\mathrm{m}}$ - potencial mátrico, $\mathrm{kPa}$;

$\theta_{\mathrm{s}}-$ umidade do solo saturado, $\mathrm{cm}^{3} \mathrm{~cm}^{-3}$;

$\theta_{r}$ - umidade do solo residual, $\mathrm{cm}^{3} \mathrm{~cm}^{-3}$;

$\alpha, \mathrm{n}, \mathrm{m}$ - parâmetros de ajuste empíricos.

Com os resultados diários do conteúdo de água no solo, determinou-se o volume de água aplicado para cada nível de reposição hídrica, sendo que nos tratamentos de $100 \%$ baseou-se na elevação da umidade do solo para a capacidade de campo. Para os demais tratamentos, foram aplicadas lâminas de acordo com a porcentagem prevista de reposição hídrica.

A área experimental foi quimicamente corrigida conforme o resultado da análise de solo e recomendação de Sousa e Lobato (2004), com aplicação de $30 \mathrm{~kg} \mathrm{ha}^{-1}$ de $\mathrm{N}$ (ureia), $120 \mathrm{~kg} \mathrm{ha}^{-1}$ de $\mathrm{P}_{2} \mathrm{O}_{5}$ (superfosfato simples) e $80 \mathrm{~kg} \mathrm{ha}^{-1}$ de $\mathrm{K}_{2} \mathrm{O}$ (cloreto de potássio). Nas parcelas em que foi prevista a aplicação de nitrogênio, este foi aplicado totalmente via água de irrigação, parcelado em dez aplicações ao longo do ciclo da cultura. 
A partir dos dados climatológicos do período experimental, foi elaborada a estimativa do balanço hídrico decendial para a cana-deaçúcar em manejo de sequeiro, empregando-se o método de Thornthwaite \& Mather (1955), sendo que a Evapotranspiração de Referência $\left(\mathrm{Et}_{0}\right)$ foi calculada segundo a equação de Penman-
Monteith-FAO/56 (ALLEN et al., 1998) (Figura 2). A precipitação total ao longo do ciclo da cultura foi de $1479,6 \mathrm{~mm}$, retirando o volume de água percolado foram computados 1019,2 mm de precipitação efetiva (PE). A evapotranspiração total do ciclo da cultura (ETc) totalizou $1817,5 \mathrm{~mm}$.
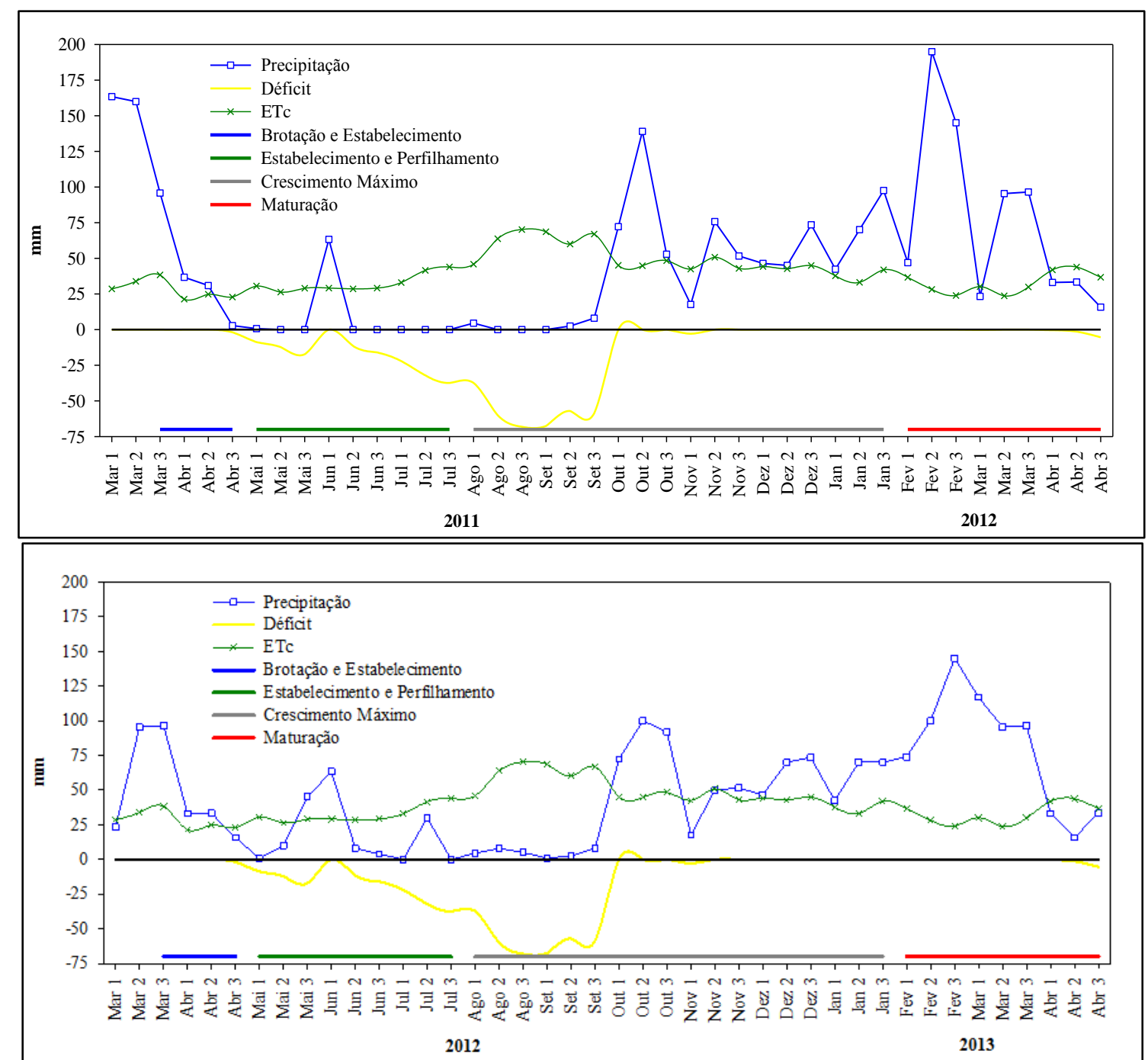

Figura 2. Balanço hídrico da cana-de-açúcar em manejo de sequeiro, ETc - Evapotranspiração da cultura, Fases da cultura (adaptado de Doorenbos e Kassam, 1994): Brotação e Estabelecimento ( $\mathrm{Kc}=0,6$ ); Estabelecimento e Perfilhamento ( $\mathrm{Kc}=0,9$ a 1,1); Crescimento Máximo $(\mathrm{Kc}=1,3)$; e Maturação ( $\mathrm{Kc}=0,7$ a 0,9$)$. Fonte: Estação Normal INMET - Rio Verde - GO.

As características morfológicas foram avaliadas mensalmente nas linhas centrais de cada parcela, quantificando: Número de Perfilhos (NPE) e Número de Plantas (NPA).

$\mathrm{O}$ número de plantas foi determinado a partir da contagem de todas as plantas que continham acima de seis folhas completamente expandidas e o número de perfilhos foi determinado a partir da contagem de todas as plantas que continham menos de seis folhas completamente expandidas.

Foram demarcadas três plantas aleatórias em um metro linear no centro da linha dupla principal, para análise mensal das variáveis. 
Após o termino das avaliações, os dados foram agrupados segundo os estádios fenológicos da cana-de-açúcar. Conforme Diola \& Santos (2012), os estádios de desenvolvimento da cana-de-açúcar se dividem em quatro fases: (a) Brotação e estabelecimento da cultura; (b) Perfilhamento: estende-se desde o final da brotação até 120 dias após o plantio; (c) Desenvolvimento vegetativo e crescimento dos colmos: inicia-se logo após a fase de perfilhamento até 270 dias após o plantio; (d) Maturação: fase de síntese e acúmulo de açúcar, que dura de 270-300 até 360 dias após o plantio. Sendo que neste estudo as avaliações iniciaram após o estádio (a) Brotação e estabelecimento da cultura, além disso, cada estádio foi chamado de fase: (b) Fase I - perfilhamento; (c) Fase II crescimento máximo; (d) Fase III - maturação.

Os resultados das variáveis biométricas obtidos em cada fase de desenvolvimento, foram submetidos à análise da variância pelo teste $\mathrm{F}$ ao nível de $5 \%$ de probabilidade, e em casos de significância, foi realizada a análise de regressão para os níveis de reposição hídrica, enquanto para o fator aplicação de nitrogênio e ciclo, as médias foram comparadas entre si pelo teste Tukey à 5\% de probabilidade, utilizando-se o programa estatístico SISVAR ${ }^{\circledR} \quad$ (FERREIRA, 2011).

\section{RESULTADOS E DISCUSSÃO}

As fases da cana-de-açúcar analisadas com relação a variável NPE, apresentaram efeito significativo para a interação entre Reposição Hídrica - RH x Ciclo - C, na fase I, e isoladamente para o fator $\mathrm{C}$, na fase II. Estes resultados evidenciam a relação direta entre a irrigação por gotejamento subsuperficial e os ciclos avaliados na cana-de-açúcar para a NPE na fase inicial (Tabela 2).

A RH não apresentou efeito significativo na fase II, além disso, o CV apresentou a variação da fase I para II de 14,25 a 17,16\%, pode-se observar ainda, que no decorrer do crescimento e desenvolvimento, o $\mathrm{CV}$ tendeu a aumentar da fase I para a fase II (Tabela 2). Estes resultados são justificados pelo fato da ocorrência da grande morte de perfilhos ocorrido nesta fase, relacionado principalmente com a característica da variedade utilizada. Estes resultados estão de acordo com os resultados obtidos por Cintra et al. (2008) os primeiros estágios de desenvolvimento (emergência e perfilhamento) da cana-de-açúcar são os que mais sofrem prejuízos, pois são mais sensíveis ao déficit hídrico, o que fundamenta os resultados aqui apresentados.

Tabela 2. Resumo da análise de variância para os fatores Reposição Hídrica, Nitrogênio e Ciclo nas diferentes fases da cana-de-açúcar, Rio Verde, Goiás, safras 2011/2012 e 2012/2013.

\begin{tabular}{lccc}
\hline & \multirow{2}{*}{ FV } & GL & \multicolumn{2}{c}{ Número de Perfilhos (NPE) } \\
\cline { 3 - 4 } & & \multicolumn{2}{c}{ Fase I II } \\
\cline { 3 - 4 } Reposição Hídrica (RH) & 4 & $30,8637^{* *}$ & $2,4187^{\mathrm{ns}}$ \\
Nitrogênio (N) & 1 & $16,7811^{\mathrm{ns}}$ & $4,7531^{\mathrm{ns}}$ \\
Ciclo (C) & 1 & $80,0400^{* *}$ & $222,7781^{* *}$ \\
Interação RH x N & 4 & $6,2327^{\mathrm{ns}}$ & $2,2375^{\mathrm{ns}}$ \\
Interação RH x C & 4 & $19,7587^{*}$ & $2,3562^{\mathrm{ns}}$ \\
Interação N x C & 1 & $1,2500^{\mathrm{ns}}$ & $4,7531^{\mathrm{ns}}$ \\
Interação RH x N x C & 4 & $10,1205^{\mathrm{ns}}$ & $0,7687^{\mathrm{ns}}$ \\
\hline Bloco & 3 & $10,7993^{\mathrm{ns}}$ & $6,5947^{\mathrm{ns}}$ \\
Resíduo & 57 & 6,8286 & 1,9610 \\
CV & & 14,25 & 17,16 \\
\hline
\end{tabular}

${ }^{\text {ns }}$ não significativo; ${ }^{* *} ;{ }^{*}$ significativo respectivamente a $1 \%$ e $5 \%$ de significância segundo teste F. FV - Fontes de variação; GL - Grau de liberdade; QM - Quadrado médio; CV - Coeficiente de Variação. 
Segundo Oliveira et al. (2004) o perfilhamento na cana-de-açúcar é crescente até o sexto mês após o plantio e a partir deste período inicia-se a redução no número de perfilhos, decorrente da competição, por luz, área, água e nutrientes refletindo, assim, na diminuição e paralisação do processo, além da morte dos perfilhos mais jovens; apesar disto, eles verificaram que os altos perfilhamentos de 30 e 29 plantas por metro linear, aos 60 DAP.

O NPE analisado isoladamente quanto ao fator $\mathrm{C}$ na fase II, apresentou média superior para cana-soca quando comparado a cana-planta, conforme Tabela 3.

Tabela 3. Teste de médias para o fator $\mathrm{C}$ nas diferentes fases da cana-de-açúcar, Rio Verde, Goiás, safras 2011/2012 e 2012/2013.

\begin{tabular}{cc}
\hline $\mathrm{C}$ & Número de Perfilhos (NPE) \\
\cline { 2 - 2 } Cana-planta & Fase II \\
Cana-soca & $2,1000 \mathrm{~b}$ \\
& $5,4375 \mathrm{a}$ \\
\hline
\end{tabular}

* Médias seguidas de mesma letra nas colunas não diferem entre si segundo teste Tukey a 5\% de probabilidade; C - ciclo.

O desdobramento do NPE para fator RH x $\mathrm{C}$ na fase I, adequou-se a relação linear, com $\mathrm{R}^{2}$ de $98,55 \%$ para cana-soca, indicando que apenas $1,45 \%$ das variações não são explicadas pela variação da $\mathrm{RH}$ aplicada na fase I. Pode-se observar que a cada $25 \%$ de RH, houve o incremento de 1,50 perfilhos, que corresponde a $6,73 \%$, totalizando incrementos de até 6 perfilhos, que corresponde a $26,92 \%$ para $\mathrm{RH}$ de $100 \%$, conforme Figura 3.

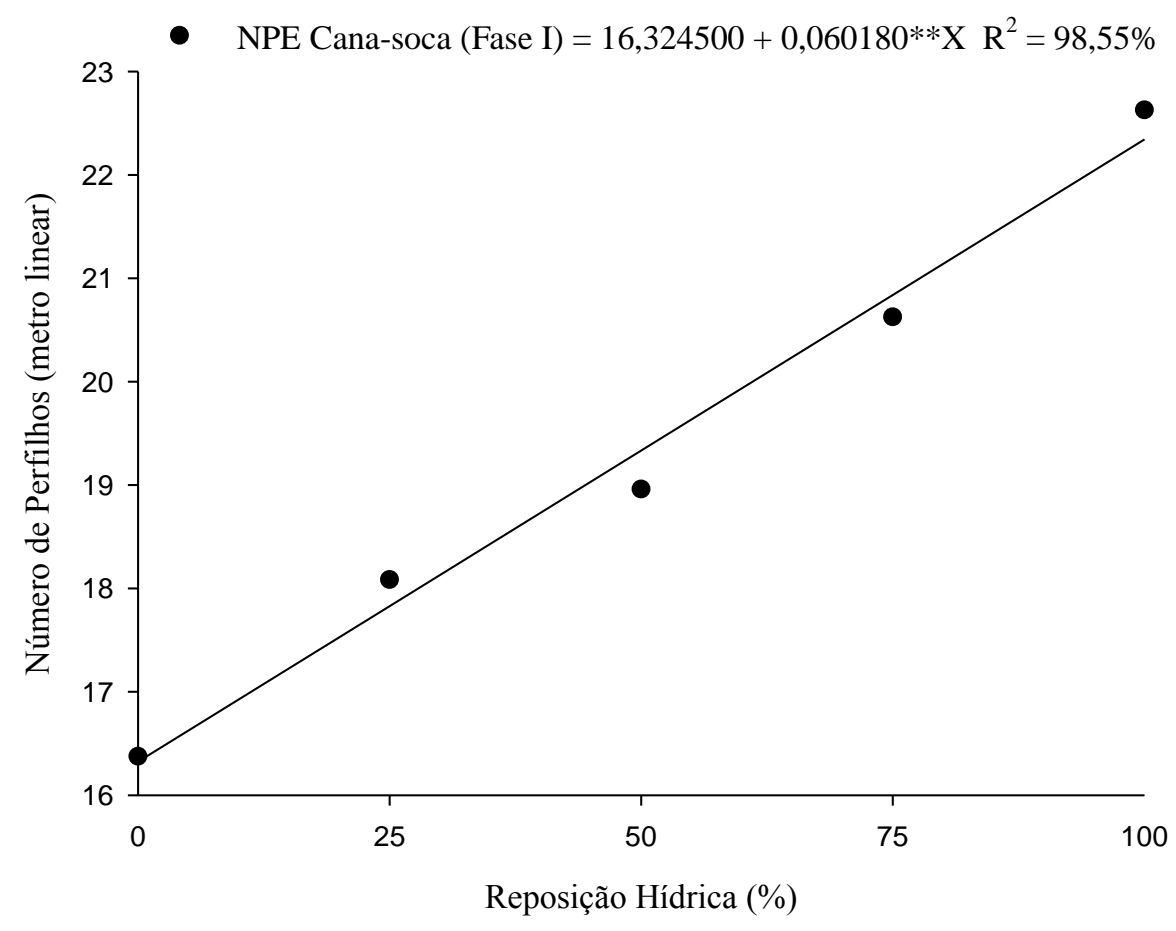

Figura 3. Número de perfilhos em função da Reposição Hídrica na Fase I da cana-de-açúcar, Rio Verde, Goiás, safras 2011/2012 e 2012/2013. ${ }^{* *}$ significativo a p<0,01 segundo teste $F$. 
Os resultados deste trabalho estão expressos em metro linear, porém, correspondem ao dobro dos resultados encontrados por Silva et al. (2012) ao longo do ciclo, onde o valor máximo constatado foi 42,5 perfilhos $\mathrm{m}^{-2}$, assim como, Almeida et al. (2008) (40,5 perfilhos $\mathrm{m}^{-2}$ ), para a variedade RB 92579, contudo conduzida a partir do mês de março em área mantida sob irrigação, no ciclo de soca, no Estado de São Paulo. Porém, coincide com os valores obtidos por Oliveira et al.
(2005), que encontraram máximo perfilhamento variando de 20 a 30 plantas $\mathrm{m}^{-2}$, entre 3,5 a 4 meses depois do plantio, em canaplanta, com pico de perfilhamento obtido aos 120 DAP.

$\mathrm{Na}$ fase I, o desdobramento do fator $\mathrm{C}$ dentro RH apresentou efeito significativo na $\mathrm{RH}$ de $100 \%$, sendo que a maior média foi observada em cana-soca, com o aumento de $24,31 \%$, quando comparada a cana-planta, conforme Tabela 4.

Tabela 4. Teste de média para o desdobramento do fator $\mathrm{C}$ x RH na fase I de cultivo da cana-de-açúcar, Rio Verde, Goiás, safras 2011/2012 e 2012/2013.

\begin{tabular}{cc}
\hline $\mathrm{C}$ & Número de Perfilhos (NPE) \\
\cline { 2 - 2 } Cana-planta & $100 \%$ \\
Cana-soca & Médias $(\mathrm{m})$ \\
& $17,1250 \mathrm{~b}$ \\
\hline
\end{tabular}

* Médias seguidas de mesma letra nas colunas não diferem entre si segundo teste Tukey a 5\% de probabilidade; C - ciclo.

As fases da cana-de-açúcar analisadas com relação a variável NPA, apresentaram efeito significativo para a interação entre RH x C, nas fases I e II. Estes resultados evidenciam a relação direta entre a irrigação por gotejamento subsuperficial e os ciclos avaliados na cana-de-açúcar para a NPA. O CV apresentou valores da fase I para II de 11,48 a $11,45 \%$, valor que confirma a precisão experimental dos dados apesar da ocorrência da morte de plantas nestas fases avaliadas (Tabela 5).

Tabela 5. Resumo da análise de variância para os fatores Reposição Hídrica, Nitrogênio e Ciclo nas diferentes fases da cana-de-açúcar, Rio Verde, Goiás, safras 2011/2012 e 2012/2013.

\begin{tabular}{|c|c|c|c|}
\hline \multirow{2}{*}{$\mathrm{FV}$} & \multirow{2}{*}{ GL } & \multicolumn{2}{|c|}{ Número de Plantas (NPA) } \\
\hline & & Fase I & Fase II \\
\hline & & \multicolumn{2}{|c|}{ QM } \\
\hline Reposição Hídrica (RH) & 4 & $180,6990^{\text {*** }}$ & $141,7062^{* * *}$ \\
\hline Nitrogênio $(\mathrm{N})$ & 1 & $71,5176^{\mathrm{ns}}$ & $37,8125^{\mathrm{ns}}$ \\
\hline Ciclo (C) & 1 & $40336,3656^{* *}$ & $8221,5125^{* *}$ \\
\hline Interação RH x N & 4 & $21,7902^{\mathrm{ns}}$ & $14,2187^{\mathrm{ns}}$ \\
\hline Interação RH x C & 4 & $174,2968^{* *}$ & $111,6062^{* *}$ \\
\hline Interação N x C & 1 & $26,8424^{\mathrm{ns}}$ & $5,0000^{\mathrm{ns}}$ \\
\hline Interação RH x N x C & 4 & $33,9976^{\mathrm{ns}}$ & $66,1562^{\mathrm{ns}}$ \\
\hline Bloco & 3 & $60,2429^{\mathrm{ns}}$ & $16,3583^{\mathrm{ns}}$ \\
\hline Resíduo & 57 & 24,1571 & 29,0622 \\
\hline $\mathrm{CV}$ & & 11,28 & 11,45 \\
\hline
\end{tabular}


O desdobramento do NPA para fator RH x $\mathrm{C}$ nas fases I e II, adequou-se respectivamente a relação linear e quadrática, com $\mathrm{R}^{2}$ de 82,53 e $58,45 \%$, respectivamente, para cana-soca, indicando que 17,47 e 41,55\% das variações não são explicadas pela variação da RH aplicada nas fases I e II, quando comparada a $0 \%$ aumentou 11,$21 ; 17,24$ e 19,75 e $19,33 \%$, respectivamente na cana-soca para $25 ; 50 ; 75$ e $100 \%$ de RH na fase II. Já na fase I, o ponto máximo para NPA ocorreu na RH de $83,85 \%$, conforme Figura 4.

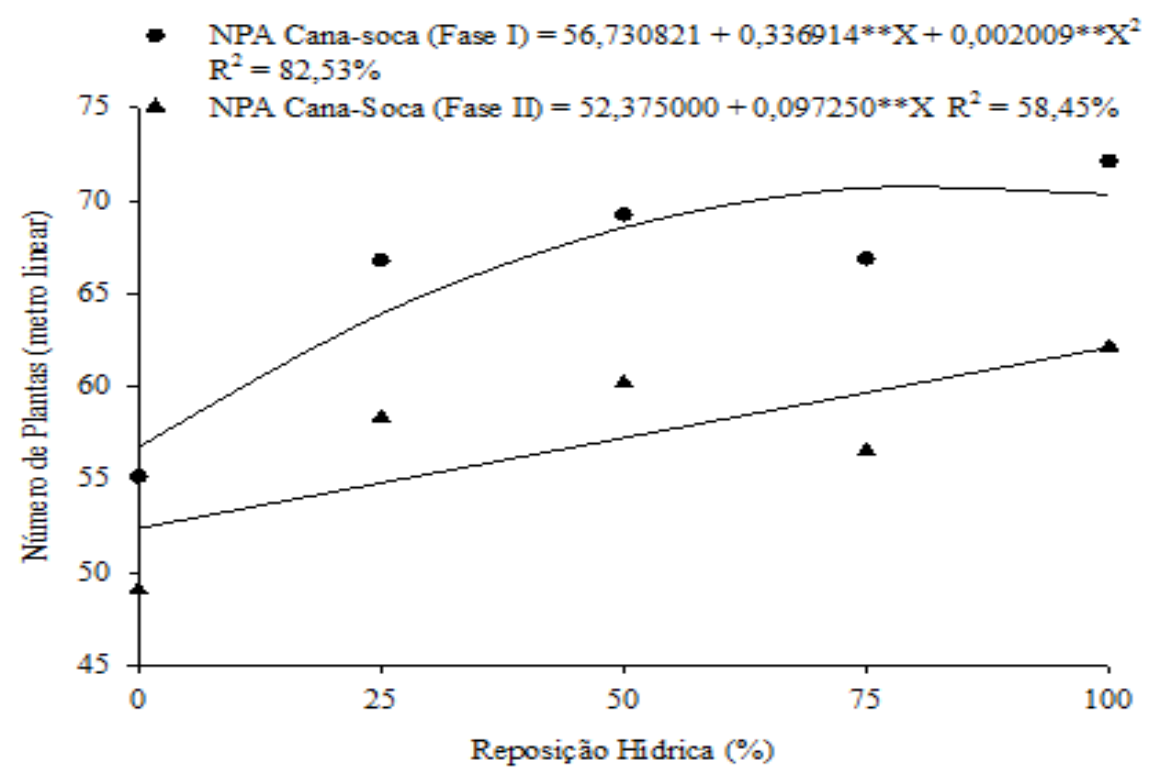

Figura 4. Número de plantas em função da Reposição Hídrica na cana-de-açúcar, Rio Verde, Goiás, safras 2011/2012 e 2012/2013. $\quad{ }^{* * *}$ significativo a p<0,01 segundo teste $F$.

O perfilhamento inicial da cana-de-açúcar foi uniforme e constante até alcançar o pico máximo de perfilhos, seguido por um período de senescência dos mesmos. Resultados semelhantes foram obtidos por Bezuidenhout et al. (2003) que classificou o crescimento da cultura da cana-de-açúcar de acordo com o perfilhamento, tendo separado o mesmo em três fases: a) formação dos perfilhos primários; b) período de grande perfilhamento; e c) período de senescência dos perfilhos.

Nas fases I e II, o desdobramento do fator $\mathrm{C}$ dentro RH apresentou efeito significativo em todos os níveis de $\mathrm{RH}$, sendo que as maiores médias foram observadas na cana-soca, quando comparada a cana-planta, conforme Tabela 6.

Tabela 6. Teste de média para o desdobramento do fator Ciclo x RH na cana-de-açúcar, Rio Verde, Goiás, safras 2011/2012 e 2012/2013.

\begin{tabular}{|c|c|c|c|c|c|}
\hline \multicolumn{6}{|c|}{ Número de Plantas (NPA) } \\
\hline $\mathrm{C}$ & $0 \%$ & $25 \%$ & $50 \%$ & $75 \%$ & $100 \%$ \\
\hline Fase I & & & ....... m . & & \\
\hline Cana-planta & $21,41 \mathrm{~b}$ & $18,33 \mathrm{~b}$ & $21,45 b$ & $22,58 \mathrm{~b}$ & $21,87 \mathrm{~b}$ \\
\hline Cana-soca & $55,16 \mathrm{a}$ & $66,79 \mathrm{a}$ & $69,25 \mathrm{a}$ & $66,87 \mathrm{a}$ & $72,12 \mathrm{a}$ \\
\hline Fase II & & & ........ m . & & \\
\hline Cana-planta & $36,18 \mathrm{~b}$ & $34,31 \mathrm{~b}$ & $35,06 \mathrm{~b}$ & $39,87 \mathrm{~b}$ & $39,37 \mathrm{~b}$ \\
\hline Cana-soca & $49,06 \mathrm{a}$ & $58,31 \mathrm{~b}$ & $60,18 \mathrm{a}$ & $56,50 \mathrm{a}$ & $62,12 \mathrm{a}$ \\
\hline
\end{tabular}

* Médias seguidas de mesma letra nas colunas não diferem entre si segundo teste Tukey a 5\% de probabilidade; $\mathrm{C}$ - ciclo. 
Segundo Cintra et al. (2008) a fase inicial do desenvolvimento da cana-de-açúcar é a que proporciona maior quebra na produção, quando sofre estresse hídrico, a irrigação nessa fase é crucial para o aumento da produtividade, principalmente na cana-soca, colhida no início da safra. Dessa forma, e muito importante obter um perfilhamento e um número de plantas que formem um estande de plantas adequados. Isso é possível com o uso da irrigação, aumentando a chance de se obter produtividades satisfatórias.

\section{CONCLUSÕES}

Houve relação direta entre aplicação da irrigação por gotejamento subsuperficial e ciclo de cultivo, nas variáveis número de perfilhos e número de plantas, analisadas ao longo das fases de crescimento e desenvolvimento da cana-deaçúcar.

A cana-soca mostrou ter maior dependência de irrigação com relação a canaplanta quanto as variáveis número de perfilhos e número de plantas.

A interação entre reposição hídrica e o ciclo influenciaram em todas as fases de cultivo da cana-de-açúcar. Houve dependência entre estes fatores para as variáveis, número de perfilhos e número de plantas.

A reposição hídrica apresentou maior efeito para número de plantas em condições de cana-soca, quando dependente do ciclo e número de perfilhos em cana-soca, quando não dependente do ciclo.

\section{AGRADECIMENTOS}

Os autores agradecem ao Ministério da Ciência e Tecnologia (MCT), ao Conselho Nacional de Desenvolvimento Científico e Tecnológico (CNPq) e à Coordenação de Aperfeiçoamento de Pessoal de Nível Superior (Capes).

\section{REFERÊNCIAS BIBLIOGRÁFICAS}

ALLEN, R. G.; PEREIRA, L. S.; RAES, D. Crop evapotranspiration. Rome: FAO, (FAO Irrigation and Drenage Paper, 56), p. 297, 1998.

ALMEIDA, A. C. S.; SUZA, J. L.; TEODORO, I.; BARBOSA, G. V. S.; MOURA FILHO, G.; FERREIRA JÚNIOR, R. A. Desenvolvimento vegetativo e produção de variedades de cana-deaçúcar em relação à disponibilidade hídrica e unidades térmicas. Ciência e Agrotecnologia, v. 32, n. 05, p. 1441-1448, 2008.

BEZUIDENHOUT, C. N.; O’LEARY, G. J.; SINGELS, A.; BAJIC, V. B. A process based model to simulate changes in tiller density and light interception of sugarcane crops. Agricultural Systems. v.76, n.2, p.589-599, 2003.

CINTRA, J. E. V.; FERREIRA, G. H.; BRASIL, R. P. C. Viabilidade da irrigação suplementar na fase inicial de desenvolvimento da cana-deaçúcar (Saccharum ssp.) em regiões com déficit hídrico. Nucleus, Edição Especial, 2008.

DANTAS NETO, J; FIGUEREDO, J. L. C; FARIAS, C. H. A; AZEVEDO, H. M; AZEVEDO, C. A. V. Resposta da cana-deaçúcar, primeira soca, a níveis de irrigação e adubação de cobertura. Revista Brasileira de Engenharia Agrícola e Ambiental, v.10, n.2, p.283-288, 2006.

DEVOS, K. M. Grass genome organization and evolution. Curr Opin Plant Biol. 2010, vol. 13, pp. 139-145.

DIOLA, V.; SANTOS, F. Fisiologia. In: SANTOS, F.; BORÉM, A.; CALDAS, C. (Eds.). Cana-de-açúcar: bioenergia, açúcar e etanol tecnologias e perspectivas. 2 ed. Viçosa: Os Editores, 2012. p. 25-49.

DOORENBOS, J.; KASSAM, A.H. Efeito da água no rendimento das culturas. Campina Grande: UFPB, 1994. 306p. (Estudos FAO: Irrigação e Drenagem, 33) 
EMPRESA BRASILEIRA DE PESQUISA AGROPECUÁRIA. Sistema brasileiro de classificação de solos. 2.ed. Rio de Janeiro: Ministério da Agricultura e do abastecimento, 2006. 306p.

FERREIRA, D. F. Sisvar: a computerstatisticalanalysis system. Ciência e Agrotecnologia, v. 35, n.6, p. 1039-1042, 2011.

INMAN-BAMBER, N. G.; SMITH, D. M. Water relations in sugarcane and response to water deficits. Field Crops Research, Amsterdam, v. 92, p. 185-202, 2005.

MACHADO, E. C.; LANDELL, M. G. A. Respostas biométricas e fi siológicas ao defi cit hídrico em cana-de-açúcar em diferentes fases fenológicas. Pesq. agropec. bras., Brasília, v.44, n.12, p.1575-1582, dez. 2009.

MARCUZZO, F. F. N. Sistemas de otimização hidráulica e econômica de rede de irrigação localizada usando algoritmos genéticos. 2008, 361 f. Tese (Doutorado em Hidráulica e Saneamento) - Escola de Engenharia de São Carlos, Universidade de São Paulo, 2008.

MONTEITH, J. L. Principles of environmental plysics. Edward Arnold, London, 241p. 1973.

OLIVEIRA, E. C. A.; OLIVEIRA, R. I.; ANDRADE, B. M. T.; FREIRE. F. J.; LIRA JÚNIOR, M. A.; MACHADO, P. R. Crescimento e acúmulo de matéria seca em variedades de cana-de-açúcar cultivadas sob irrigação plena. Revista Brasileira de Engenharia Agrícola e Ambiental, Campina Grande, PB, v,14, n.9, p. 951-960, mar. 2010.

OLIVEIRA, R. A.; DAROS, E.; ZAMBON, J. L. C.; WEBER, H.; IDO, O. T.; ZUFELLATORIBAS, K. C.; KOEHLER, H. S.; SILVA, D. K. T. Crescimento e desenvolvimento de três cultivares de cana-de-açúcar, em cana-planta, no estado do Paraná: taxas de crescimento. Scientia Agrária, Curitiba, v. 6, n. 1/2, p. 85-89, 2005.
OLIVEIRA, R. A.; DAROS, E.; ZAMBON, J. L. C.; WEBER, H.; IDO, O. T.; ZUFELLATORIBAS, K. C.; KOEHLER, H. S.; SILVA, D. K. T. Crescimento e desenvolvimento de três cultivares de cana-de-açúcar, em cana-planta, no estado do Paraná. Scientia Agrária, Curitiba, v. 5, n. 1/2, p. 87-94, 2004.

SEGATO, S. V.; MATTIUZ, C. F. M.; MOZAMBANI, A. E. Aspectos fenológicos da cana-de-açúcar. In: SEGATO, S. V.; Pinto, A. S.; Jendiroba, E. Nóbrega, J. C. M. (org.) Atualização em produção de cana-de-açúcar. Piracicaba: CP 2, 2006. p. 19-36.

SILVA, T. G. F.; MOURA, M. S. B.; ZOLNIER, S.; CARMO, J. F. A.; SOUZA, L. S. B. Biometria da parte aérea da cana soca irrigada no Submédio do Vale do São Francisco. Rev. Ciênc. Agron., Fortaleza, vol.43, n.3, 2012.

SMIT, M. A.; SINGELS, A. The response of surgarcane canopy development to water stress. Field Crops Research, Cambridge, v. 98, p. 9197, 2006.

SOUSA, D.M.G.; LOBATO, E. Cerrado: Correção do solo e adubação. 2.ed. Brasília, Embrapa Informação Tecnológica, 2004. 416p. THORNTHWAITE, C.W.; MATHER, J.R. The water balance, Laboratory of Climatology, Centerton, v.8, n.1, p.1-14, 1955.

van GENUCHTEN M.T.; LEIJ, F. J.; YATES, S. R. RETEC, Code for quantifying the hydraulic functions of unsaturated soils: version 6.02. Riverside: University of California, 2009.

van GENUCHTEN, M.T. A closed form equation for predicting the hydraulic conductivity of unsaturated soils. Soil Science Society of America Journal, v. 44, p. 892-898, 1980.

WIEDENFELD, B.; ENCISO, J. Sugarcane responses to irrigation and nitrogen in semiarid south Texas. Agronomy Journal, v.100, p.665671, 2008. 